\title{
Erratum to: The effect of the metal-on-metal hip controversy on Internet search activity
}

\author{
Nigel Phelan · John C. Kelly $\cdot$ David P. Moore • \\ Patrick Kenny
}

Published online: 4 March 2014

(C) Springer-Verlag France 2014

\section{Erratum to: Eur J Orthop Surg Traumatol \\ DOI 10.1007/s00590-013-1399-3}

Unfortunately, one of the co-authors' name was not listed in the original publication. The missing author name and affiliations are given below:

Mr. David P. Moore

Department of Orthopaedic Surgery, Tallaght Hospital, Dublin, Ireland

Department of Orthopaedic Surgery, Our Lady's Children's Hospital Crumlin, Dublin, Ireland

The online version of the original article can be found under doi:10.1007/s00590-013-1399-3.

N. Phelan $(\bowtie)$ J. C. Kelly · P. Kenny

Department of Orthopaedic Surgery, Cappagh National

Orthopaedic Hospital, Dublin, Ireland

e-mail: nigelphelan@rcsi.ie

D. P. Moore

Department of Orthopaedic Surgery, Tallaght Hospital,

Dublin, Ireland

D. P. Moore

Department of Orthopaedic Surgery, Our Lady's Children's

Hospital Crumlin, Dublin, Ireland 